\title{
ESTRUTURA E DESIGUALDADE DA RENDA NA REGIÃO NORDESTE, DE 2004 A 2015
}

\author{
Nathalia da Silva Colombo ${ }^{1}$ \\ Carlos Roberto Ferreira ${ }^{2}$
}

RESUMO: Este estudo objetiva analisar o comportamento da distribuição do rendimento domiciliar per capita na região Nordeste e compará-lo com o Brasil, a fim de observar disparidades. Para isso, utiliza-se a metodologia de decomposição do índice de Gini que consiste em determinar a contribuição de cada parcela do rendimento para a desigualdade total, utilizando dados da Pesquisa Nacional por Amostra de Domicílios (PNAD) de 2004 a 2015. Observou-se que a região Nordeste, comparada ao Brasil, evidenciou na maioria das parcelas do rendimento domiciliar per capita predomínio de maiores razões de concentração, com exceção da parcela 9, que inclui benefícios de programas sociais, ressaltando a existência de uma tendência concentradora de rendimento na região.

Palavras-Chave: Distribuição da renda. Índice de Gini. Região Nordeste. Rendimento domiciliar per capita.

ABSTRACT: This study aims to analyze the behavior of the per capita domiciliary income distribution at the Northeast region of Brazil and compare it to the whole country, looking for diparities. In this paper it was used the Gini's index decomposition methodology along with data of the National Survey by Household Sample (PNAD) from 2004 to 2015. The Northeast region, compared to Brazil, showed in most of the plots of household income per capita the predominance of higher concentration ratios, with the exception of the 9th portion that includes social program benefits, highlighting the existence of a concentration tendency of income in the region.

Keywords: Distribution of income. Gini index. Northeast region. Per capita domiciliary income.

\footnotetext{
${ }^{1}$ Mestranda do Programa de Pós-Graduação de Economia Regional (UEL), graduada em Ciências Econômicas (UEL). E-mail: nathaliascolombo@gmail.com.

${ }^{2}$ Graduação em Economia (UEL). Mestrado em Economia Aplicada (UFV) e Doutorado em Economia Aplicada (USP). Professor associado da Universidade Estadual de Londrina.E-mail: robert@uel.br.
} 


\section{INTRODUÇÃO}

O acompanhamento da evolução da distribuição da renda, tal qual outros indicadores sociais, faz-se necessário para afirmar quais são as transformações advindas do crescimento econômico brasileiro ao longo da história. Também verificar se existiram melhorias qualitativas e ressaltar quem foram os beneficiários de tais transformações, tendo em vista que o Brasil faz parte dos países com maiores quadros de desigualdade do mundo (PNUD 2016).

A manutenção do alto nível de desigualdade de rendimentos é capaz de frear o desenvolvimento econômico, o que pode afetar negativamente o processo de melhoria do bem-estar social. O Brasil caracteriza-se por grandes diversidades regionais e entre estados da mesma região. Os estados das regiões Sul e Sudeste apresentam menor concentração de rendimentos, por serem regiões mais desenvolvidas, devido ao alto crescimento econômico local ao longo do tempo. Enquanto as demais regiões, Centro-Oeste, Norte e Nordeste, possuem níveis de desigualdade superiores, devido a limitações de desenvolvimento econômico atreladas ao mercado de trabalho e educação.

Há um histórico de concentração de rendimentos enraizado na história brasileira desde o período colonial, até mesmo o desenvolvimento industrial na segunda metade do século XX possuiu características favoráveis para o aumento da concentração de renda. A desigualdade da renda, na década de 1960, aumentou com maior intensidade entre as pessoas economicamente ativas no setor urbano e principalmente nas regiões Sul e Sudeste. Enquanto na década de 1970, o maior aumento da população economicamente ativa se deu no meio rural, devido a aceleração do processo de modernização da agricultura, e a maior desigualdade é observada nas regiões Nordeste, Norte e Centro-Oeste.

Os anos de 1980 e 1990 foram caracterizados por acentuadas instabilidades, tanto econômicas quanto institucionais, altas taxas de inflação e aumento do déficit público. Principalmente na segunda metade da década de 1980 e primeiros anos da década de 1990, os índices de desigualdade da renda cresceram. A inflação e os sistemas de indexação foram importantes fatores de transferência de renda para os mais ricos.

O Plano Real conseguiu frear muitos problemas econômicos, mas não foi capaz de criar oportunidades para que as camadas mais pobres se apropriassem de 
uma parcela maior da renda nacional, dessa forma, a desigualdade da renda termina a década de 1990 ainda muito elevada.

Com o surgimento dos programas de transferências de renda em 2001, notase uma redução geral da pobreza no país, mais expressivamente nas regiões menos favorecidas. A participação das rendas provenientes de transferências aumentou significativamente mais no Nordeste do que nas demais regiões, entre 2004 e 2005, conforme verificou o estudo de Hoffmann (2007). Entretanto é preciso frisar que a condição social observada em regiões como o Nordeste, não atingiu o nível das regiões de maior crescimento econômico. Sendo assim, é relevante estudar as regiões que não partilharam do mesmo crescimento econômico que o constatado no eixo Centro-Sul, ao longo da história brasileira, para que se identifique o que as leva a margem e como superar tais desníveis.

A presente pesquisa tem como objetivo geral verificar a distribuição do rendimento domiciliar per capita na região Nordeste, entre 2004 e 2015. A renda domiciliar per capita total será dividida em nove parcelas de rendimento, utilizando como base de dados a Pesquisa Nacional de Amostras de Domicílios (PNAD). A investigação culmina no cálculo da decomposição do Índice de Gini do Brasil, região Nordeste e seus estados.

O estudo está focado na análise da região Nordeste, objetivando especificamente: i) calcular e decompor o Índice de Gini nacional e da região Nordeste; ii) verificar a composição das fontes da renda domiciliar per capita declarada na PNAD; iii) observar o comportamento de progressividade ou regressividade de cada fonte da renda e iv) identificar os fatores que explicam tal comportamento.

O trabalho é estruturado em cinco partes, incluindo esta introdução, seguida por uma revisão teórica sobre a distribuição da renda no Brasil ao longo do período analisado, considerando o foco na Região Nordeste. A terceira parte contempla considerações sobre a base de dados e a metodologia da decomposição do índice de Gini. Os resultados acerca da distribuição de renda no Nordeste, são analisados na quarta seção. Por fim, a conclusão do tema discutido. 


\section{A DISTRIBUIÇÃO DA RENDA NO BRASIL E NA REGIÃO NORDESTE}

Os estudos quantitativos a respeito da distribuição da renda no Brasil iniciaram a partir do primeiro Censo Demográfico Nacional em 1960, e apontavam um cenário de elevada concentração de rendimentos. No entanto, a desigualdade da renda brasileira não pode ser explicada apenas pelos dez anos anteriores a divulgação do Censo, a concentração da renda está no âmago da formação econômica do Brasil, desde os tempos coloniais escravocratas.

Furtado (2007), aponta que a concentração da renda no Brasil tem origem com as capitanias hereditárias e o modo de produção colonial baseado no Plantation. Tais características, que limitam o desenvolvimento econômico, perduram ao longo da história brasileira e é possível identificá-las até mesmo nos anos de 1950.

Os ciclos econômicos brasileiros foram, em suma, geradores de graves desigualdades, tanto da renda quanto regionais e fundiárias. Ao analisar brevemente o ciclo cafeeiro observa-se que o período agroexportador trouxe a concentração regional, tendo dinâmica econômica desenvolvida no eixo Centro-Sul, deixando as demais regiões aquém do crescimento econômico da época.

As concentrações fundiária e de rendimentos eram associadas aos latifundiários do café, pois estes eram os grandes possuidores das terras e rendimentos nacionais. Posteriormente, com a crise internacional de 1929, somada a crise cafeeira, o governo provisório adota políticas como a de valorização do café, mantendo os problemas de concentração da renda. Adiante, os empresários do setor agroexportador, a elite agrícola, tornaram-se a nova elite industrial brasileira após 1930, como analisa Tavares (1972) e Furtado (1968).

A divulgação do Censo de 1970 manifesta a persistência do problema da distribuição de rendimentos no país, evidenciando o aumento da desigualdade da renda ao longo dos anos de 1960. Esse aumento foi respaldado pela compressão salarial, que aumentou o excedente do produto e este foi repassado as camadas mais ricas.

Dessa forma, mesmo que fosse evidente o crescimento econômico através dos ganhos de produtividade, gerados pelas modernidades técnicas, agrícolas e industriais, os benefícios alcançados não foram compartilhados por toda a população. Metade não foi atingida, $40 \%$ foi atingida marginalmente e apenas $10 \%$ 
da população beneficiou-se do crescimento econômico ocorrido no período, evidenciado por Hoffmann e Kageyama (1986).

Os anos de 1968 a 1973 no Brasil foram marcados pelo "Milagre Econômico". O crescimento econômico nesse período foi grande e intenso, todavia, ao passo que houve crescimento econômico, a concentração da renda também se elevou. Enquanto o país enriquecia, a massa salarial não acompanhava os mesmos passos. Bonelli e Ramos (1995) evidenciam que nas décadas de 1960 e 1970, todos os estratos elevaram seus rendimentos absolutos, embora em ambas as décadas os ganhos dos estratos mais ricos tenham sido altamente superiores.

A redistribuição da renda nessas duas décadas novamente ocorreu de forma a repassar dos menos favorecidos aos mais favorecidos. Apesar dos empregadores serem os possuidores dos maiores rendimentos no período, também houve a promoção da classe média, composta por técnicos e profissionais liberais com maior qualificação, consequência de políticas de incentivo a indústria e, sobretudo as indústrias que utilizavam tecnologias avançadas.

O aumento da demanda por profissionais mais qualificados cresceu, ao passo que a oferta desses profissionais não evoluiu. Sendo assim, o repasse de baixo para cima na distribuição da renda, não foi só repassado aos empregadores, como também aos membros da nova classe média, reforçando ainda mais as diferenças de rendimentos se comparada a população de menor rendimento, como explica Singer (1973).

Em 1980, o Brasil é considerado a oitava economia industrial do mundo, entretanto, para este mesmo ano, Hoffmann e Kageyama (1986), apontam que 50\% da população vivia com menos de meio salário mínimo ao mês e o país seguia entre as nações com maior grau de desigualdade do mundo.

A inflação na década de 1980 era considerada um grave problema a ser solucionado, no ano de 1983 alcançou o patamar de $200 \%$ ao ano. A partir de 1986 , foram adotados sucessivos planos de estabilização. O Plano Cruzado foi implantado em 1986 e um ano após era possível verificar que as taxas de inflação da antiga moeda, o cruzeiro, foram ainda maiores. No ano seguinte, o Plano Bresser é adotado e fracassa no mesmo ano, logo, não solucionando o grave problema inflacionário da época.

Ferreira (2006), verificou que após o Plano Cruzado efetivar-se houve uma tendência sistemática no crescimento da desigualdade da renda, tendo seu ápice 
em 1989. Bonelli e Ramos (1995), apontam que, na década de 1980, existiu uma associação positiva relacionada a inflação e desigualdade.

Durante toda a década de 1990 a desigualdade da renda apresentou níveis elevados, Ramos e Vieira (2001) apontam que a concentração de renda no final da década é resultado do processo inflacionário crescente dos primeiros anos e das tentativas malsucedidas de estabilização inflacionária vividas desde a década de 1980, somente em 1994 através do Plano Real soluciona-se o problema inflacionário.

Dessa forma, pondera-se que no final dos anos de 1990 a desigualdade não pode ser explicada pelos níveis inflacionários, pois estes estavam controlados, e sim por um caráter intrínseco concentrador, o qual não foi superado por meio das políticas estabilizadoras e só poderia ser enfrentado através de políticas sociais distributivas.

A partir de 2001, a desigualdade da renda brasileira diminui e segue com a mesma tendência nos anos seguintes. Esse fenômeno pode ser associado a criação dos programas sociais como Auxílio Gás, Bolsa Escola, Bolsa Alimentação e Cartão Alimentação, no governo Fernando Henrique Cardoso. Estes programas foram integrados e modificados no governo Lula, dando origem ao Bolsa Família, programa de complementação direta da renda, tendo como objetivo o combate à pobreza no curto prazo.

No entanto, a queda na desigualdade da renda não é derivada exclusivamente dos programas de transferência de renda, Schwartzman (2006) e Soares (2006) indicam outros fatores como: o aumento do salário mínimo, que impactou também aposentadorias e pensões, a educação e a redução do desemprego. É importante ressaltar que políticas ligadas ao salário mínimo e associadas a queda do desemprego são preeminentes para a análise da redução da desigualdade, por conseguinte redução da pobreza. Isto ocorre, pois, a maior parte da população está ligada ao salário mínimo.

Hoffmann (2009) confirma a hipótese de Schwartzman (2006), demonstrando que no período 2001 a 2007 o fator que mais influenciou, cerca de 50\%, a queda da desigualdade foi o rendimento dos trabalhadores do setor privado. A desigualdade da renda seguiu uma tendência decrescente durante todo o período dos anos 2000 e segue rumos decrescentes até o governo Dilma, em 2011. Oliveira e Silveira Neto (2013), apontam que a diminuição da desigualdade da renda, entre 2003 e 2011, foi 
resultado de melhorias na escolaridade e dos programas de redistribuição da renda. Enfatiza que estes programas mesmo tendo foco individual corroboraram para a redução da desigualdade entre as regiões brasileiras.

Em 2015, a concentração da renda brasileira completou 14 anos de decrescimento, e pode-se observar uma queda geral dos rendimentos reais das pessoas, fato que não ocorrida desde 2004. Isso demonstra que a queda da desigualdade da renda em 2015, diferente dos anos anteriores, não é explicada por uma melhoria na condição das classes mais pobres e sim por uma diminuição dos rendimentos das camadas mais ricas, também conhecido como "nivelamento por baixo".

A região Nordeste não se exclui da tendência distributiva nacional, tal qual o Brasil, a região melhorou seus índices distributivos desde o início dos anos 2000. De acordo com Bessa (2013), o Nordeste possui propensão a maiores impactos com relação a políticas distributivas, devido a histórico de alta concentração de rendimentos. Acerca da trajetória econômica do Nordeste, Falvo (2011) analisa que o Nordeste passou por um processo de expansão industrial que atingiu de forma mais intensa o litoral e especificamente as atuais metrópoles de Fortaleza, Recife e Salvador.

Esse crescimento industrial fez com que a população com maior nível de educação formal buscasse nessas cidades melhores oportunidades financeiras. Por consequência, a população rural e do interior, manifestou o grave problema da pobreza e desigualdade da renda.

Assim, mesmo com a queda da desigualdade ao longo dos anos 2000, a região Nordeste ainda é uma das regiões brasileiras mais afetadas pelo elevado grau de concentração de renda, portanto, uma das mais dependentes dos programas de transferência de renda. Giambiagi et al (2016) destacam que em 2011 havia cerca de 22 milhões de brasileiros em situação de extrema pobreza e destes $60 \%$ viviam na região Nordeste.

\section{BASE DE DADOS E METODOLOGIA}

A seguir estão descritas respectivamente, a base de dados e a metodologia utilizadas neste trabalho. 


\subsection{BASE DE DADOS}

As informações utilizadas neste trabalho foram retiradas da Pesquisa Nacional por Amostra de Domicílios (PNAD), realizada pelo Instituto Brasileiro de Geografia e Estatística (IBGE), no período de 2004 a 2015. Esta é uma pesquisa anual por amostragem probabilística de domicílios, realizada em todo o território nacional.

Os dados fornecidos pela PNAD são base para pesquisas que buscam analisar particularidades da população brasileira, como exemplo educação, trabalho e rendimento. Segundo as notas metodológicas do IBGE (2004-2015), cada amostra da PNAD representa uma parcela da população total, dessa forma foi aplicado o fator de expansão da amostra, o qual usa estimadores de razão cuja variável independente é a projeção da população residente de cada Unidade da Federação.

Para o desenvolvimento deste trabalho, os domicílios com rendimento não declarados foram excluídos da análise, sendo avaliados apenas os domicílios particulares permanentes com declaração da renda domiciliar. A partir da soma dos rendimentos dos moradores da unidade domiciliar, define-se o rendimento mensal domiciliar, nesta soma são exclusas pessoas com menos de 10 anos e pessoas que residam na unidade nas condições de pensionista, empregado doméstico ou parente de empregado doméstico (IBGE, 2004-2015).

Para Hoffmann (2002), é importante ressaltar que apesar dos dados das PNADs serem de boa qualidade, deve-se levar em conta que existem restrições nesta base de dados. Isso ocorre principalmente por conta da existência de uma propensão a subdeclarações dos rendimentos, presumivelmente dos mais altos, fazendo com que a renda nacional e o nível de desigualdade sejam subestimados.

Os dados referentes a rendimentos também podem derivar de informações das declarações de imposto de renda, Hoffmann (2016) analisa que ao unir dados da PNAD com os de rendimentos do imposto de renda obtêm-se índices de desigualdade superiores aos verificados apenas com dados da PNAD.

\subsection{METODOLOGIA}

Embora existam inúmeras medidas do grau de desigualdade da distribuição da renda, como mostra Hoffmann (1998), neste trabalho utilizou-se o índice de Gini, 
que obedece a condição Pigou-Dalton ${ }^{3}$. Do índice de Gini é feita a decomposição em nove parcelas da população. Faz-se também a decomposição da mudança do índice de Gini, distinguindo a progressividade ou regressividade de cada parcela da renda domiciliar per capita.

Hoffmann (1998) demonstra a Curva de Lorenz e a apresenta da seguinte maneira. Considerando-se uma população com $n$ pessoas, e $x_{i}$ a renda do $i$-ésimo indivíduo, ordena-se os valores de maneira que:

(1)

$$
x_{1} \leq x_{2} \leq \cdots \leq x_{i}
$$

A proporção acumulada da população é dada por:

(2)

$$
p_{i}=\frac{i}{n}
$$

E o correspondente para a renda é:

(3)

$$
\phi_{i}=\frac{1}{n \mu} \sum_{j=1}^{n} x_{i}
$$

Em que $\mu$ é a renda média, dada por:

(4)

$$
\mu=\frac{1}{n} \sum_{j=1}^{n} x_{i}
$$

A Curva de Lorenz é obtida pela relação entre os pares de valores de $p_{i}$ e $\phi_{i}$. O índice de Gini (ou Coeficiente de Gini) se dá pelo quociente da área entre a linha de perfeita igualdade e a Curva de Lorenz (denominado $\alpha$ ), e o seu valor limite $(0,5)$, ou seja:

\footnotetext{
${ }^{3}$ A condição de Pigou-Dalton estabelece que as medidas de desigualdade devem ter seus valores aumentados quando há transferências regressivas de renda.
} 
(5)

$$
G=\frac{\alpha}{0,5} \rightarrow 2 \alpha
$$

Definindo $\beta$ a área entra a Curva de Lorenz e o eixo das abscissas, pode-se dizer que a área total do triângulo se dá por, $\alpha+\beta=0,5$. Com isso, pode-se reescrever a equação (5) como:

(6)

$$
G=1-2 \beta
$$

De maneira semelhante, pode-se considerar que a renda $x_{i}$ é composta por $k$ parcelas, ou seja $x_{i}=\sum_{i=1}^{k} x_{h i}$, e a média da $h$-ésima parcela se dá por:

(7)

$$
\mu_{h}=\frac{1}{n} \sum_{i=1}^{n} h_{i}
$$

E a participação da $h$-ésima parcela na renda total como:

(8)

$$
\varphi_{h}=\frac{\mu_{h}}{\mu}
$$

Analogamente, Pyatt, Chen e Fei (1980) definiram a curva de concentração como sendo a relação da proporção acumulada da parcela $h$ em função da variação da proporção acumulada da população $\left(p_{i}\right)$. Então, do mesmo modo que para o índice de Gini, define-se a Razão de Concentração da parcela $h\left(C_{h}\right)$ como sendo:

(9)

$$
C_{h}=1-2 \beta_{h}
$$

Em que $\beta_{h}$ é a área entre a curva de concentração da $h$-ésima parcela e os eixos das abscissas.

Com as equações (8) e (9), pode-se demonstrar que: 
(10)

$$
G=G-\sum_{h=1}^{k} \varphi_{h} C_{h}
$$

E como $\sum_{h=1} \varphi_{h}=1$, pode-se reescrever a equação (10) como:

$$
G=G-\sum_{h=1}^{k} \varphi_{h} \pi_{h}
$$

Com:

$$
\pi_{h}=G-C_{h}
$$

A equação (12) é definida como a medida de progressividade, pois a relacionando com a equação (11), no caso de $\pi_{h}>0\left(C_{h}<G\right)$, corresponderá a parcelas progressivas, ou seja, que contribuem para decréscimo do coeficiente de Gini (desconcentrando renda), e no caso inverso, em que $\pi_{h}<0\left(C_{h}>G\right), x_{h i}$ será uma parcela regressiva (concentrando renda).

Neste trabalho a decomposição do rendimento domiciliar per capita foi dividida em nove parcelas, como apresentado a seguir:

1- Renda do trabalho de Empregados do Setor Privado;

2- Renda do trabalho de Militar e Funcionário Público Estatutário;

3- Renda do trabalho de Conta Própria;

4- Renda do trabalho de Empregadores;

5- Aposentadorias e pensões "oficiais";

6- Outras aposentadorias e pensões;

7- Doações feitas por pessoas de outros domicílios

8- Rendimentos de aluguéis;

9- Outros Rendimentos: Juros, dividendos, transferências de programas oficiais. 
A renda do trabalho é dividida em quatro parcelas, que vai da parcela 1 a parcela 4, conforme a natureza do trabalho, e é composta pelos rendimentos brutos de pessoas com 10 anos ou mais.

Os rendimentos de aposentadorias e pensões, parcelas 5 e 6 , são pagamentos realizados pelo Estado, institutos de previdência, seguradoras ou fundos de pensão. A renda proveniente de doações, parcela 7, é doada exclusivamente por pessoas que não residem na mesma unidade domiciliar. Os rendimentos de aluguéis, parcela 8, incluem locação de imóveis, sublocações, arrendamentos, locação de meios de produção e animais. Outros rendimentos, parcela 9, contemplam os juros de aplicações financeiras de renda fixa ou caderneta de poupança e as transferências de renda feitas pelos programas sociais do governo, como Bolsa Família, Renda Mínima, Benefício de Prestação Continuada, entre outros.

\section{ANÁLISE DOS RESULTADOS}

Tendo realizado a coleta dos dados das PNADs e desenvolvido a metodologia proposta, calculou-se o índice de Gini e a decomposição do índice de Gini para o Brasil, Região Nordeste e seus nove estados. Os cálculos foram realizados para o período entre 2004 e 2015, excetuando-se 2010, ano em que foi realizado o Censo Demográfico e não houve coleta de dados para a PNAD.

A tabela 1 apresenta os resultados referentes à evolução do Índice de Gini para o Brasil, região Nordeste e estados desta região. Pode-se verificar que de forma geral, houve uma redução da desigualdade da renda per capita no período 2004-2015, tanto para o Brasil quanto para a região Nordeste, embora essa situação não possa ser observada para todos os estados nordestinos. 
Tabela 1 - Índice de Gini para o Brasil, Região Nordeste e Estados da Região Nordeste, de 2004 a 2015.

\begin{tabular}{c|c|c|c|c|c|c|c|c|c|c|c}
\hline ANO & BR & NE & AL & BA & CE & MA & PB & PE & PI & RN & SE \\
\hline 2004 & 0,5701 & 0,5814 & 0,5725 & 0,5554 & 0,5745 & 0,6085 & 0,5902 & 0,6058 & 0,5885 & 0,5693 & 0,5587 \\
2005 & 0,5672 & 0,5698 & 0,5646 & 0,5536 & 0,5775 & 0,5193 & 0,5778 & 0,5852 & 0,5893 & 0,5954 & 0,5527 \\
2006 & 0,5604 & 0,5718 & 0,6236 & 0,5567 & 0,5462 & 0,5957 & 0,5626 & 0,5798 & 0,5988 & 0,5569 & 0,5577 \\
2007 & 0,5535 & 0,5632 & 0,6072 & 0,5528 & 0,5471 & 0,5549 & 0,5948 & 0,5581 & 0,5931 & 0,5594 & 0,5395 \\
2008 & 0,5437 & 0,5561 & 0,5791 & 0,5583 & 0,5375 & 0,5199 & 0,5828 & 0,5636 & 0,5724 & 0,5496 & 0,5357 \\
2009 & 0,5397 & 0,5561 & 0,5689 & 0,5557 & 0,5428 & 0,5366 & 0,5876 & 0,5516 & 0,5536 & 0,5569 & 0,5733 \\
2011 & 0,5290 & 0,5431 & 0,5222 & 0,5532 & 0,5366 & 0,5406 & 0,5364 & 0,5255 & 0,5073 & 0,5590 & 0,5556 \\
2012 & 0,5259 & 0,5342 & 0,4978 & 0,5476 & 0,5237 & 0,5487 & 0,5274 & 0,5067 & 0,5437 & 0,5292 & 0,5394 \\
2013 & 0,5250 & 0,5354 & 0,5215 & 0,5569 & 0,5123 & 0,5591 & 0,5218 & 0,5000 & 0,5127 & 0,5385 & 0,5568 \\
2014 & 0,5151 & 0,5133 & 0,4969 & 0,5257 & 0,5030 & 0,5272 & 0,5097 & 0,5048 & 0,4993 & 0,4943 & 0,4827 \\
2015 & 0,5144 & 0,5121 & 0,4837 & 0,5092 & 0,4911 & 0,5401 & 0,5236 & 0,5211 & 0,5067 & 0,5055 & 0,4799 \\
\hline
\end{tabular}

Fonte: Elaboração própria a partir de IBGE - PNADs de 2004 a 2015

Essa constante queda da desigualdade ao longo do período analisado, é vista por Hoffmann (2009) como resultado não somente do aumento das transferências de renda, mas principalmente das condições do mercado de trabalho, relacionadas a políticas de valorização do salário mínimo e aumento da escolaridade.

Pode-se inferir que para a região Nordeste, as transferências de renda são fundamentais para a queda da desigualdade ao longo dos anos. Araújo e Morais (2015), destacam que de 2004 a 2011 a fonte de rendimento que inclui as transferências de renda foi responsável por $28,05 \%$ da redução da desigualdade na região. Oliveira e Silveira Neto (2013), apontam que a ação dos programas sociais de transferência de renda, mesmo não tendo objetivo in loco, atingiu de forma mais acentuada as regiões mais pobres como Norte e Nordeste, dessa forma contribuindo para a redução da desigualdade do país.

A partir dos dados observados na tabela 1, nota-se que em 2014 o resultado do índice de Gini é de 0,5151 e tem uma pequena queda no ano de 2015, passando para 0,5144. De acordo com Hoffmann (2017), pode ser que o índice de Gini de 2015 esteja subestimado devido a subdeclarações de rendimentos, uma vez que neste ano houve queda no rendimento real de $7 \%$ e esse fator potencialmente levaria a um aumento do índice de Gini. Na tabela 1 também é possível verificar que os estados do Maranhão, Paraíba, Pernambuco, Piauí e Rio Grande do Norte, apresentam aumento no índice de Gini de 2014 para 2015. Essa mudança pode ser um reflexo da crise econômica enfrentada pelo país, que atinge primeiro os estados mais pobres.

A tabela 2 mostra a Participação percentual das Parcelas do rendimento domiciliar per capita na Renda Total para o Brasil. A maior parte das parcelas não 
expressou crescimento ou decrescimento significativo, com exceção da parcela 4 que diminuiu sua participação cerca de $35,5 \%$, refletindo a crise econômica que atingiu principalmente os micro e pequenos empresários, e da parcela 9, outros rendimentos, que dobrou a participação refletindo o aumento de beneficiários do programa Bolsa Família nesta parcela, ambos de 2004 para 2015.

Tabela 2 - Participação percentual $\left[(\%) \varphi_{h}\right]$ dos componentes do rendimento domiciliar per capita. Brasil, de 2004 a 2015.

\begin{tabular}{|c|c|c|c|c|c|c|c|c|c|c|}
\hline \multirow{2}{*}{ ANO } & \multicolumn{9}{|c|}{ Parcelas } & \multirow{2}{*}{ TOTAL } \\
\hline & 1 & 2 & 3 & 4 & 5 & 6 & 7 & 8 & 9 & \\
\hline 2004 & 39,67 & 10,08 & 15,46 & 11,21 & 18,05 & 1,46 & 0,73 & 1,73 & 1,61 & 100 \\
\hline 2005 & 40,08 & 9,81 & 14,75 & 11,32 & 18,12 & 1,61 & 0,72 & 1,81 & 1,78 & 100 \\
\hline 2006 & 39,24 & 10,62 & 14,17 & 11,91 & 17,93 & 1,51 & 0,71 & 1,73 & 2,18 & 100 \\
\hline 2007 & 40,51 & 10,85 & 15,57 & 10,06 & 17,94 & 1,44 & 0,55 & 1,48 & 1,60 & 100 \\
\hline 2008 & 41,12 & 10,87 & 13,66 & 10,93 & 18,14 & 1,29 & 0,50 & 1,68 & 1,81 & 100 \\
\hline 2009 & 40,84 & 11,22 & 13,54 & 10,61 & 18,76 & 1,32 & 0,44 & 1,55 & 1,72 & 100 \\
\hline 2011 & 42,73 & 10,88 & 15,44 & 8,28 & 18,15 & 1,21 & 0,26 & 1,09 & 1,96 & 100 \\
\hline 2012 & 42,02 & 10,53 & 15,18 & 9,25 & 17,91 & 1,15 & 0,27 & 1,25 & 2,44 & 100 \\
\hline 2013 & 42,35 & 10,74 & 14,61 & 9,48 & 18,32 & 1,12 & 0,25 & 1,14 & 1,99 & 100 \\
\hline 2014 & 41,74 & 10,70 & 15,15 & 9,07 & 18,23 & 1,27 & 0,37 & 1,18 & 2,29 & 100 \\
\hline 2015 & 40,71 & 11,42 & 15,04 & 8,27 & 19,79 & 1,19 & 0,39 & 1,06 & 2,13 & 100 \\
\hline
\end{tabular}

Fonte: Elaboração própria a partir de IBGE - PNADs de 2004 a 2015 Nota: 1 - Empregados do setor privado; 2 - Militares e funcionários públicos estatutários; 3 - Trabalho por conta própria; 4 - Trabalho de empregadores; 5 - Aposentadorias e pensões "oficiais"; 6 - Outras aposentadorias e pensões; 7 - Doações feitas por pessoas de outros domicílios; 8 - Aluguéis; 9 - Outros rendimentos: juros, dividendos, transferências de programas oficiais como o programa Bolsa Família.

Com relação a composição do rendimento a parcela 1, renda do trabalho de empregados do setor privado, foi observada uma tendência constante em torno de $40 \%$, entre 2004 e 2015, e é o maior componente da renda domiciliar per capita. Por outro lado, a parcela 7, doações feitas por outros domicílios, possuiu a menor participação na composição do rendimento total, apresentando uma queda de 46,6\% de 2004 para 2015.

A parcela 4, renda do trabalho de empregadores, expressou um decrescimento contínuo ao longo do período analisado, totalizando uma queda de aproximadamente $26,2 \%$ de 2004 para 2015, ano em que apresentou a menor contribuição para o rendimento per capita total. A maior queda do período é vista de 2009 para 2011, passando de 10,61\% para 8,28\%, uma diminuição de $28 \%$ da participação da parcela.

De acordo com estudos de Santos (2015), os pequenos empregadores aumentaram seus rendimentos em 2011, aproximando-se do nível de empregadores de maior rendimento. No entanto, grande parte dos empregadores de menor 
rendimento optaram por fechar suas empresas e retornar ao mercado de trabalho, o que pode explicar a queda da participação.

De forma oposta, a parcela 9, outros rendimentos, incluindo transferências de programas oficiais, demonstrou que de 2004 para 2009 houve um crescimento na participação de 1,61 \% para 1,72\%. Quando comparado 2015 com relação a 2009 observa-se um grande, crescimento de aproximadamente $28,83 \%$, passando de $1,72 \%$ para $2,13 \%$, devido a ampliação no número de beneficiários, tanto do programa Bolsa Família quanto do Benefício por Prestação Continuada (BPC).

Em 2004 cerca de 6,6 milhões de famílias eram atendidas pelo Bolsa Família, já em 2015 o programa ampliou-se e chegou a 13,9 milhões de famílias beneficiárias. O BPC também foi expandido, totalizando uma variação positiva de 143,3\%, de 2004 para 2015, no número de beneficiários (MDS, 2018). As parcelas de aposentadorias e pensões, 5 e 6, somadas compõem o segundo maior componente da renda total. Pode-se observar que estas parcelas apresentaram uma participação de forma constante na renda total domiciliar per capita ao longo do período analisado.

Ferreira (2003), aponta que essa tendência pode ser explicada pelas mudanças ocorridas nas regras previdenciárias a partir de 1988, possibilitando aumento do número de beneficiários urbanos e rurais, além do aumento da expectativa de vida e do envelhecimento da população brasileira, que colaboram para que mais pessoas deixem o mercado de trabalho e solicitem o benefício previdenciário.

A tabela 3 mostra a participação das parcelas do rendimento domiciliar per capita na renda total do Nordeste. 
Tabela 3 - Participação percentual $\left[(\%) \varphi_{h}\right]$ dos componentes do rendimento domiciliar per capita. Nordeste, de 2004 a 2015.

\begin{tabular}{|c|c|c|c|c|c|c|c|c|c|c|}
\hline \multirow{2}{*}{ ANO } & \multicolumn{9}{|c|}{ Parcelas } & \multirow{2}{*}{ TOTAL } \\
\hline & 1 & 2 & 3 & 4 & 5 & 6 & 7 & 8 & 9 & \\
\hline 2004 & 33,37 & 12,35 & 16,49 & 9,19 & 21,73 & 1,44 & 1,08 & 1,02 & 3,33 & 100 \\
\hline 2005 & 34,28 & 11,40 & 15,82 & 10,17 & 21,29 & 1,51 & 1,02 & 1,25 & 3,26 & 100 \\
\hline 2006 & 33,64 & 12,51 & 15,27 & 10,35 & 20,82 & 1,12 & 0,96 & 1,11 & 4,22 & 100 \\
\hline 2007 & 34,63 & 12,58 & 16,29 & 7,89 & 21,65 & 1,48 & 0,85 & 0,90 & 3,73 & 100 \\
\hline 2008 & 35,42 & 12,65 & 14,41 & 9,44 & 21,13 & 1,22 & 0,82 & 1,19 & 3,72 & 100 \\
\hline 2009 & 35,34 & 13,05 & 13,63 & 8,39 & 22,32 & 1,25 & 0,68 & 1,20 & 4,14 & 100 \\
\hline 2011 & 35,62 & 12,75 & 15,41 & 7,39 & 22,03 & 1,19 & 0,35 & 0,88 & 4,38 & 100 \\
\hline 2012 & 35,23 & 12,20 & 15,04 & 7,95 & 21,85 & 1,22 & 0,46 & 0,92 & 5,13 & 100 \\
\hline 2013 & 35,84 & 12,92 & 13,94 & 7,63 & 21,73 & 1,18 & 0,35 & 1,08 & 5,33 & 100 \\
\hline 2014 & 36,17 & 12,19 & 14,70 & 6,74 & 21,98 & 1,24 & 0,59 & 0,95 & 5,44 & 100 \\
\hline 2015 & 34,16 & 12,82 & 14,84 & 6,59 & 23,63 & 1,20 & 0,59 & 0,87 & 5,30 & 100 \\
\hline
\end{tabular}

Fonte: Elaboração própria a partir de IBGE - PNADs de 2004 a 2015. Nota: 1 - Empregados do setor privado; 2 - Militares e funcionários públicos estatutários; 3 - Trabalho por conta própria; 4 - Trabalho de empregadores; 5 - Aposentadorias e pensões "oficiais"; 6 - Outras aposentadorias e pensões; 7 - Doações feitas por pessoas de outros domicílios; 8 - Aluguéis; 9 - Outros rendimentos: juros, dividendos, transferências de programas oficiais como o programa Bolsa Família.

Tal qual para o Brasil, a maior participação é observada na parcela 1 e apresentou crescimento de 2004 para 2009, porém encerrou 2015 com um decrescimento. A participação verificada em 2015 é semelhante à do início do período, 2004.

A parcela 4, renda do trabalho de empregadores, apresentou constante queda, totalizando uma redução de $28,3 \%$ no período de 2004 a 2015. Enquanto o maior crescimento dentre as parcelas é dado na parcela 9, que resultou em uma ascensão de aproximadamente 59,2\% no período de 2004 a 2015.

Apesar da parcela 1 ser a maior tanto para o Brasil quanto para o Nordeste, em 2004 a participação desta parcela no Nordeste foi cerca de 15,9\% menor do que no Brasil. Já em 2009 essa diferença passou a ser de 13,5\% e em 2015 subiu para $16 \%$. Essa distinção reflete as diferenças do mercado de trabalho nordestino comparado ao nacional. (ARAÚJO; MORAIS, 2015).

A seguir está representada graficamente a diferença entre a participação da parcela do rendimento do trabalho privado no Brasil e na Região Nordeste. 
Gráfico 1 - Participação da Renda do trabalho de Empregados do Setor Privado, no Brasil e Nordeste, de 2004 a 2015.

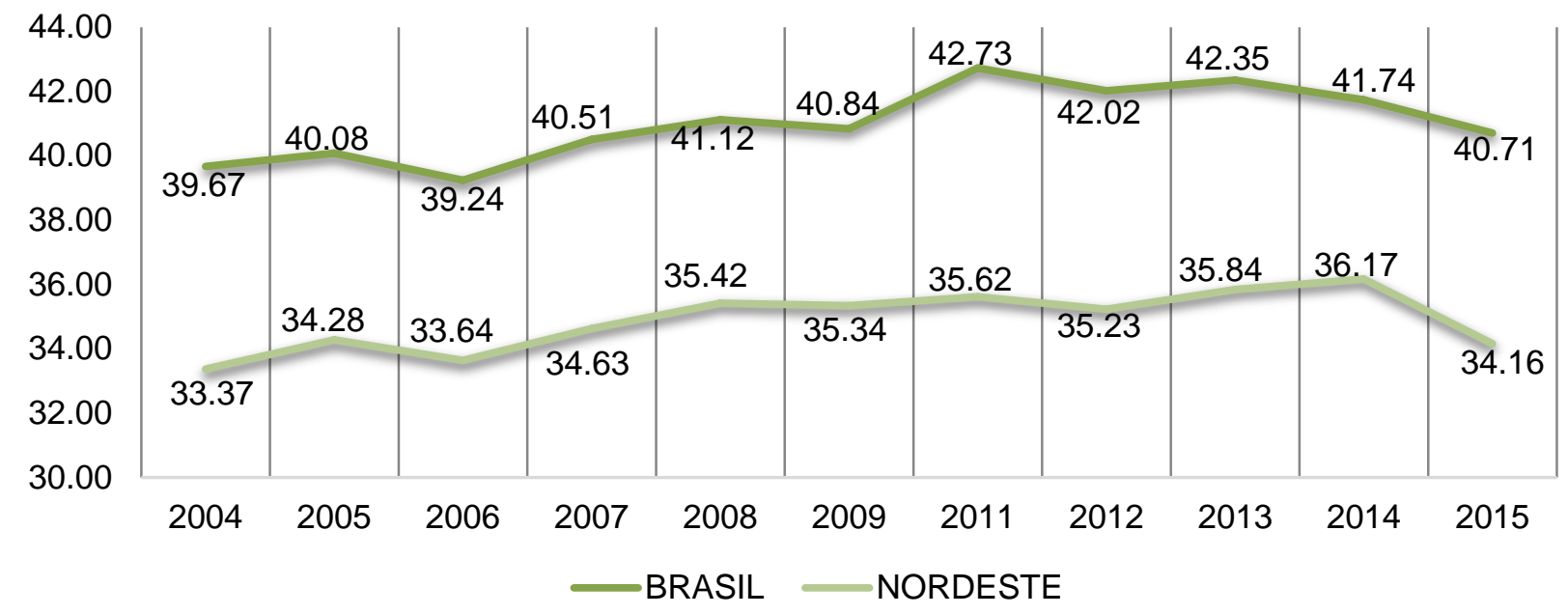

Fonte: Elaboração própria a partir de IBGE - PNADs de 2004 a 2015

A participação das parcelas de aposentadorias e pensões na região Nordeste é superior comparada a participação verificada no Brasil, as parcelas 5 e 6, somadas representam em média cerca de $23 \%$ da renda total nordestina, menor apenas que a parcela 1. Entende-se, portanto, que nos domicílios dessa região grande parte da população depende de aposentadorias e pensões como única fonte de renda domiciliar.

Com relação a parcela 9, novamente comparando Brasil e Nordeste, observase que as transferências de renda ao longo de todo o período 2004-2015, tiveram uma participação substancialmente maior no Nordeste. O crescimento dessa parcela foi de $24,5 \%$ no Brasil e de $37,2 \%$ no Nordeste. Segundo dados do Ministério do Desenvolvimento Social (2018) mais da metade do valor total destinado ao Bolsa Família é absorvido pela região Nordeste e a região aumentou em aproximadamente 108\% o número de famílias beneficiárias do programa no período de 2004 para 2015 e o Benefício de Prestação Continuada (BPC) cresceu cerca de 104,8\% no mesmo período.

O gráfico abaixo ilustra o comportamento da parcela 9, Outros Rendimentos, ao longo do período de 2004 a 2015, no Brasil e Região Nordeste. 
Gráfico 2 - Outros Rendimentos: Juros, dividendos, transferências de programas oficiais, no Brasil e Nordeste, de 2004 a 2015.

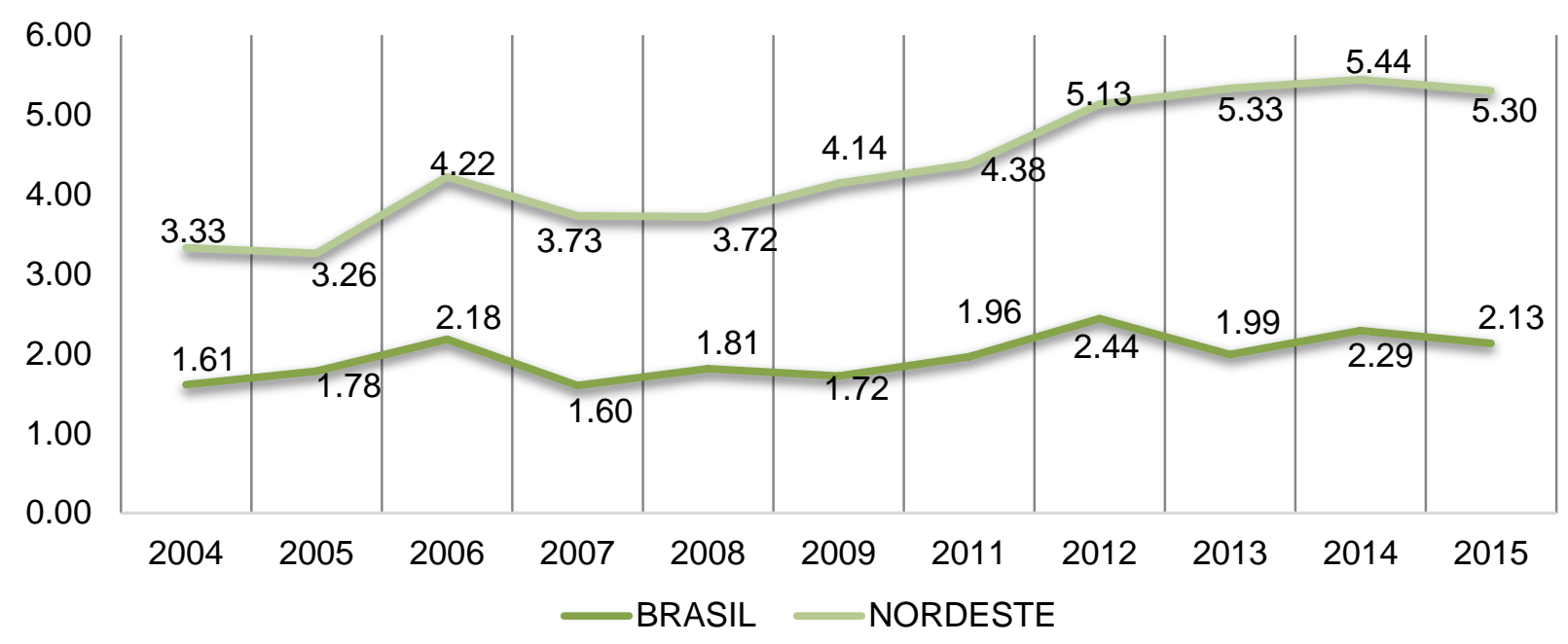

Fonte: Elaboração própria a partir de IBGE - PNADs de 2004 a 2015

As tabelas 4 e 5 ilustram, respectivamente, a razão de concentração das parcelas, decompostas a partir do índice de Gini do rendimento domiciliar per capita, para o Brasil e para a região Nordeste. Caso a razão de concentração $\left(C_{h}\right)$ seja menor que o índice de Gini (G), a parcela é progressiva e ajuda a desconcentrar renda.

Tabela 4. Razão de Concentração $\left(C_{h}\right)$ na decomposição do índice de Gini do rendimento domiciliar per capita. Brasil, de 2004 a 2015.

\begin{tabular}{|c|c|c|c|c|c|c|c|c|c|c|}
\hline \multirow{2}{*}{ ANO } & \multicolumn{9}{|c|}{ Razão de Concentração das Parcelas (Ch) } & \multirow{2}{*}{\begin{tabular}{|c|} 
GINI \\
BR $(G)$
\end{tabular}} \\
\hline & 1 & 2 & 3 & 4 & 5 & 6 & 7 & 8 & 9 & \\
\hline 2004 & 0,4727 & 0,7353 & 0,4947 & 0,8556 &, 5942 & 0,5716 & 0,4638 & 0,7886 & 1583 & 0,5701 \\
\hline 2005 & 0,4730 & 0,7382 & 0,4798 & 0,8525 & 0,5874 & 0,6147 & 0,4131 & 0,7911 & 0,2341 & 0,5672 \\
\hline 2006 & 0,4559 & 0,7479 & 0,4797 & 0,8561 & 0,5766 & 0,5836 & 0,4448 & 0,7918 & 0,1197 & 0,5604 \\
\hline 2007 & 0,4531 & 0,7456 & 0,5121 & 0,8521 & 0,5611 & 0,5 & 0,4197 & 0,7908 & 0,0089 & 0,5535 \\
\hline 2008 & 0,4434 & 0,7416 & 0,4710 & 0,8365 & 0,5599 & 0,4949 & 0,4355 & 0,7999 & 0,0095 & 0,5437 \\
\hline 2009 & 0,4375 & 0,7461 & 0,4702 & 0,8371 & 0,5597 & 0,4959 & 0,3922 & 0,7757 & $-0,1051$ & 0,5397 \\
\hline 2011 & 0,4435 & 0,7473 & 0,5003 & 0,8517 & 0,5308 & 0,4867 & 0,3691 & 0,7774 & $-0,0855$ & 0,5290 \\
\hline 2012 & 0,4343 & 0,7318 & 0,5072 & 0,8542 & 0,5197 & 0,4659 & 0,3241 & 0,8051 & 0,0202 & 0,5259 \\
\hline 2013 & 0,4354 & 0,7340 & 0,4990 & 0,8584 & 0,5216 & 0,4764 & 0,3482 & 0,7898 & $-0,1905$ & 0,5250 \\
\hline 2014 & 0,4252 & 0,7380 & 0,4914 & 0,8455 & 0,5160 & 0,4991 & 0,2639 & 0,7676 & $-0,1380$ & 0,5151 \\
\hline 2015 & 0,4315 & 0,7424 & 0,4682 & 0,8368 & 0,5222 & 0,4756 & 0,2430 & 0,7521 & $-0,1973$ & 0,5144 \\
\hline
\end{tabular}

Fonte: Elaboração própria a partir de IBGE - PNADs de 2004 a 2015. Nota: 1 - Empregados do setor privado; 2 - Militares e funcionários públicos estatutários; 3 - Trabalho por conta própria; 4 - Trabalho de empregadores; 5 - Aposentadorias e pensões "oficiais"; 6 - Outras aposentadorias e pensões; 7 - Doações feitas por pessoas de outros domicílios; 8 - Aluguéis; 9 - Outros rendimentos: juros, dividendos, transferências de programas oficiais como o programa Bolsa Família.

Considerando a tabela 4, observa-se que a parcela 9, que inclui as transferências de renda oficiais, foi a parcela mais progressiva, colaborando 
significativamente para reduzir a concentração de renda. Ressalta-se a importância dessa parcela, pela capacidade de atingir a população pobre e extremamente pobre, aumentando a renda e melhorando a condição socioeconômica dos beneficiários.

A tabela 4 também demonstra que a segunda maior parcela progressiva foi a parcela 7 , doações de outros domicílios, seguida pela parcela 1, renda do trabalho do setor privado. A parcela de rendimento do trabalho ajuda a não concentrar renda, à medida que o mercado de trabalho fica menos desigual por meio do aumento do nível educacional, do aumento da produtividade do trabalho, da queda do trabalho informal, entre outros.

A parcela 5, aposentadorias e pensões "oficiais", apresentou caráter regressivo, porém em baixo grau. Isso ocorre devido a composição da parcela que inclui tanto aposentadorias e pensões de alto rendimento, regressivas, quanto aposentadorias e pensões inferiores ou iguais a 1 salário mínimo, progressivas.

As aposentadorias e pensões iguais a 1 salário mínimo, são fundamentais para diminuir a desigualdade, tendo em vista que os mais pobres estão ligados a esse piso e a maioria dos aposentados e pensionistas pertencem a essa faixa. Dados da ANASPS (2018) indicam que em 2015 cerca de $70 \%$ dos beneficiários do INSS recebiam 1 salário mínimo.

A parcela 4, como mostra a tabela 4, representa o componente da renda mais regressivo durante todo o período de 2004 a 2015, ou seja, trata-se da parcela que mais colabora para o aumento da desigualdade de rendimentos. Esses dados corroboram com os estudos de Santos (2015) demonstrando que em 2011 há um aumento da razão de concentração da parcela, tornando-a ainda mais regressiva, ao passo que sua participação no rendimento total diminui. Dentre as demais parcelas regressivas estão as parcelas 2 e 8, que tem por característica tratarem de rendimentos altos e ligados a pequenos grupos da população.

A seguir está demonstrada na tabela 5 a razão de concentração, baseada na decomposição do Gini, do rendimento domiciliar per capita para a região Nordeste do Brasil. 
Tabela 5. Razão de Concentração $\left(C_{h}\right)$ na decomposição do índice de Gini do rendimento domiciliar per capita. Nordeste, de 2004 a 2015.

\begin{tabular}{c|c|c|c|c|c|c|c|c|c|c}
\hline \multirow{2}{*}{ ANO } & \multicolumn{7}{|c|}{ Razão de Concentração das Parcelas (Ch) } & GINI \\
\cline { 2 - 9 } & $\mathbf{1}$ & $\mathbf{2}$ & $\mathbf{3}$ & $\mathbf{4}$ & $\mathbf{5}$ & $\mathbf{6}$ & $\mathbf{7}$ & $\mathbf{8}$ & $\mathbf{9}$ & NE (G) \\
\hline 2004 & 0,4974 & 0,8111 & 0,4387 & 0,8938 & 0,6330 & 0,6510 & 0,4004 & 0,8278 & 0,0408 & 0,5814 \\
2005 & 0,4835 & 0,7992 & 0,4208 & 0,8961 & 0,6168 & 0,6551 & 0,3115 & 0,8422 & 0,0292 & 0,5698 \\
2006 & 0,4768 & 0,8085 & 0,4474 & 0,8996 & 0,6156 & 0,5959 & 0,3552 & 0,8372 & 0,0249 & 0,5718 \\
2007 & 0,4728 & 0,8093 & 0,4861 & 0,8889 & 0,5545 & 0,6305 & 0,3844 & 0,8248 & $-0,0221$ & 0,5632 \\
2008 & 0,4688 & 0,8103 & 0,4299 & 0,8706 & 0,5939 & 0,5394 & 0,3862 & 0,8475 & $-0,0678$ & 0,5561 \\
2009 & 0,4752 & 0,8019 & 0,4272 & 0,8652 & 0,6039 & 0,5367 & 0,3838 & 0,8440 & $-0,0557$ & 0,5561 \\
2011 & 0,4638 & 0,7948 & 0,4779 & 0,9016 & 0,5666 & 0,5514 & 0,2815 & 0,8382 & $-0,0854$ & 0,5431 \\
2012 & 0,4525 & 0,7900 & 0,4910 & 0,8934 & 0,5592 & 0,4941 & 0,2647 & 0,8389 & $-0,0863$ & 0,5342 \\
2013 & 0,4582 & 0,7923 & 0,4834 & 0,8903 & 0,5612 & 0,5342 & 0,2140 & 0,8625 & $-0,0975$ & 0,5354 \\
2014 & 0,4342 & 0,7855 & 0,4684 & 0,8774 & 0,5548 & 0,4904 & 0,1966 & 0,8565 & $-0,1050$ & 0,5133 \\
2015 & 0,4318 & 0,7928 & 0,4406 & 0,8683 & 0,5533 & 0,4590 & 0,1733 & 0,7873 & $-0,0915$ & 0,5121 \\
\hline
\end{tabular}

Fonte: Elaboração própria a partir de IBGE - PNADs de 2004 a 2015. Nota: 1 - Empregados do setor privado; 2 - Militares e funcionários públicos estatutários; 3 - Trabalho por conta própria; 4 - Trabalho de empregadores; 5 - Aposentadorias e pensões "oficiais"; 6 - Outras aposentadorias e pensões; 7 - Doações feitas por pessoas de outros domicílios; 8 - Aluguéis; 9 - Outros rendimentos: juros, dividendos, transferências de programas oficiais como o programa Bolsa Família.

Com relação a progressividade das parcelas, nota-se que a parcela que mais contribuiu para a desconcentração de renda foi a parcela 9 . Tem-se a parcela 7 como segunda parcela mais progressiva, porém em um nível inferior comparada a parcela 9. As demais parcelas progressivas, 1 e 3, apresentam baixa progressividade, ou seja, apesar de terem contribuído para a queda da concentração de renda, ainda apresentam razões de concentração elevadas.

A maior regressividade encontra-se na parcela 4, que mesmo tendo reduzido a participação no rendimento total como mostra a tabela 3, manteve elevado grau de concentração durante todo o período, apresentando seu ápice em 2011. A região Nordeste, em relação ao Brasil, apresentou maiores razões de concentração na maioria das parcelas do rendimento domiciliar per capita, com exceção da parcela 9. Assim, pode-se observar a existência de uma tendência a concentração de renda na região.

Ao analisar a evolução da parcela 1, considerando as tabelas 4 e 5, observase que tanto para o Brasil quanto para o Nordeste houve aumento do grau de progressividade ao longo do período, ou seja, a parcela passou a contribuir mais para diminuir a concentração de renda, entretanto, ainda apresentam razões de concentração elevadas.

Esse fato pode ser explicado pela composição da parcela em que os rendimentos do trabalho privado incluem tanto grandes salários de executivos 
(parcela regressiva), como também trabalhadores que recebem salário mínimo (parcela progressiva), conforme explica Hoffmann e Ney (2008).

As parcelas de aposentadorias e pensões 5 e 6, apesar de terem uma maior participação no rendimento total nordestino, apresentaram maiores graus de regressividade se comparadas ao Brasil. Isto ocorre devido ao alto número de pessoas em situação de extrema pobreza na região Nordeste, principalmente no interior dos estados nordestinos.

Nesse caso, como muitas pessoas encontram-se com rendas muito baixas, rendimentos, mesmo que sejam de um salário mínimo contribuem para aumentar a concentração de renda. Silveira Neto e Gonçalves (2007), avaliam que políticas ligadas ao salário mínimo tem maior impacto no meio rural nordestino que no meio urbano.

Ao avaliar a razão de concentração da parcela 9, pode-se observar nas tabelas 5 e 6, mais uma vez constata-se o fato de a parcela de rendimento ligada às transferências de renda ter maior importância na composição do rendimento da região Nordeste. Verifica-se que o grau de progressividade da parcela colabora expressivamente para a redução da concentração de renda no Nordeste, visto que sua participação no rendimento total nordestino aumentou ao longo do período, 2004 a 2015.

Dessa forma, observa-se que os resultados obtidos a respeito da parcela 9 estão de acordo com a literatura revisada e é normal que existam distinções entre os resultados dos programas de transferência de renda em diferentes regiões do Brasil. No Nordeste há impactos mais acentuados que no Brasil devido à alta participação no número de beneficiários dos programas assistencialistas como Bolsa Família e Benefício de Prestação Continuada (BPC).

\section{CONSIDERAÇÕES FINAIS}

Diante da decomposição do Índice de Gini em nove parcelas do rendimento domiciliar per capita, como proposto na metodologia, para o Brasil e região Nordeste, constata-se que ao longo do período de 2004 a 2015 a desigualdade, tanto no Brasil quanto no Nordeste, seguiu uma trajetória decrescente, apesar da queda nesta região apresentar-se abaixo do que foi verificado no Brasil, em média. 
Contudo, mesmo com a constante queda do índice de Gini no período, a concentração de renda no Brasil ainda é elevada, mantendo-se na casa de 0,50, valor este distante do que é visto em países desenvolvidos que apresentam índices de Gini em torno de 0,30.

A composição da renda domiciliar per capita expressou que as parcelas relacionadas ao rendimento do trabalho e aposentadorias e pensões foram as principais para o Brasil e para a região Nordeste. Para esta região, as parcelas do rendimento do trabalho apresentaram uma tendência a manterem-se constantes ao longo do período estudado, embora seja possível observar na parcela 4 uma redução da participação, indicando uma redução da renda recebida pelos empregadores.

Por outro lado, a parcela 5, aposentadorias e pensões "oficiais", da região Nordeste apresentou crescimento acima do verificado para o Brasil, assinalando a importância dessa parcela para a região, visto que em muitos locais da região Nordeste a obtenção de renda fixa mensal é incerta, seja pela falta de postos de trabalho, pela baixa qualificação da mão de obra ou até mesmo por questões climáticas.

A parcela 9, a qual inclui o programa Bolsa Família, teve um crescimento acentuado no período, de 2004 a 2015, e reflete a expansão desse programa social, principalmente na região Nordeste que em 2004 possuía aproximadamente 3,2 milhões de famílias que recebiam o benefício, chegando em 2015 com cerca de 6,9 famílias beneficiárias, totalizando um crescimento de 108,9 \%.

Além disso, verifica-se que a região possui baixa participação em todas as parcelas do rendimento per capita, com exceção apenas das parcelas referentes a transferências condicionadas e não condicionadas de renda, parcelas 5 e 9 . Depreende-se, portanto, que a renda da região Nordeste tem significativa correlação com esse tipo de rendimento.

Dessa forma, o estudo e acompanhamento das principais parcelas do rendimento domiciliar per capita se faz necessário principalmente em razão das mudanças ocorridas na economia brasileira a partir do segundo mandato do governo Dilma Rousselff, com a recessão econômica. Esse cenário desfavorável pode atingir diretamente a distribuição do rendimento domiciliar, sendo capaz de reforçar a concentração de renda no país e impactar rigorosamente no estado de bem-estar social de regiões mais vulneráveis, como a região Nordeste. 


\section{REFERÊNCIAS}

ASSOCIAÇÃO NACIONAL DOS SERVIDORES PÚBLICOS, DA PREVIDÊNCIA E DA SEGURIDADE SOCIAL. Grandes Números da Previdência Social. Disponível em: <https://www.anasps.org.br/grandes-numeros-da-previdencia-social-7/> Acesso em: 3 jul 2018

ARAUJO, J. A.; MORAIS, G. A. S. Desigualdade de Renda e sua decomposição no Brasil e nas Regiões Brasileiras. Revista Econômica do Nordeste. Fortaleza, v. 45, n. 4, mar. 2014.

BESSA, D. C. Desigualdade da renda e decomposição das parcelas de rendimento domiciliar per capita para o Brasil e região nordeste, de 1995 a 2011. Dissertação (Mestrado) - Universidade Estadual de Londrina, fevereiro 2013.

BONELLI, R.; RAMOS, L. Distribuição de renda no Brasil: avaliação das tendências de longo prazo e mudanças na desigualdade desde meados dos anos 70 . Revista de Economia Política, São Paulo, v. 13, n. 2, abr-jun. 1993.

FERREIRA, C. R. Participação das aposentadorias e pensões na desigualdade da distribuição da renda no brasil no período de 1981 a 2001. Tese (Doutorado) - Escola Superior de Agricultura Luiz de Queiroz, São Paulo, março 2003.

. Aposentadorias e distribuição da renda no Brasil: uma nota sobre o período 1981 a 2001 . Revista Brasileira de Economia, Rio de Janeiro, v. 60, n. 3, jul./set. 2006.

FALVO, J. F. Desigualdade social e desenvolvimento no nordeste metropolitano: Análise das metrópoles de Salvador, Recife e Fortaleza no período entre 1981 a 2008. Revista ABET. João Pessoa, v. X. n. 2. Jul/Dez 2011.

FURTADO, C.. Um projeto para o Brasil. Rio de Janeiro: Saga S.A., 1968. 2007. . Formação Econômica do Brasil. São Paulo: Companhia Das Letras,

GIAMBIAGI, Fabio et al. (Org.). Economia Brasileira Contemporânea 1945-2015. 3. ed. Rio de Janeiro: Elsevier, 2016.

HOFFMANN, R.. Distribuição de Renda: medidas de desigualdade e pobreza. São Paulo: EdUSP, 1998.

. A distribuição da renda no Brasil no período de 1992-2001. Economia e Sociedade. Campinas, v. 11. n. 2 (19). p. 213-235. jul./dez. 2002.

. As transferências não são a causa principal da redução na desigualdade. Econômica. Rio de Janeiro, v. 7, n. 2, p. 335-341, 2005. 
. Desigualdade de Renda no Brasil em 2005 e sua Decomposição, p. 158181 in: Análise da Pesquisa Nacional por Amostra de Domicílios - PNAD: Pobreza e desigualdade - Brasília: MTE, CGEE, 2007. 185 p.

. Desigualdade da distribuição de renda no Brasil: a contribuição de aposentadorias e pensões e de outras parcelas do rendimento domiciliar per capita. Economia e Sociedade, Campinas, v. 18, n. 1 (35), p. 213-231, abr. 2009.

. A desigualdade relevante não caiu de 2014 a 2015. Texto para Discussão n.37 do IEPE/Casa das Garças, 2016.

. Desigualdade da distribuição da renda no Brasil: o que mudou em 2015? Texto para Discussão n.38 do IEPE/Casa das Garças, 2017.

HOFFMANN, R.; DUARTE, J. C. A distribuição da renda no Brasil. Revista de Administração de Empresas, v. 12, n. 2, p. 46-66, abr./jun. 1972.

HOFFMANN, R.; KAGEYAMA, A. A. Distribuição da renda no Brasil, entre famílias e entre pessoas, em 1970 e 1980. Estudos Econômicos, v. 16, n. 1, p. 25-51, jan./abr. 1986.

HOFFMANN, R.; NEY, M. G. A recente queda da desigualdade de renda no Brasil: análise de dados da PNAD, do Censo Demográfico e das Contas Nacionais.

Econômica, Rio de Janeiro, v. 10, n. 1, p. 7-39, jun. 2008.

INSTITUTO BRASILEIRO DE GEOGRAFIA E ESTATÍSTICA. Pesquisa Nacional por Amostra de Domicílios, 2004 a 2015. Disponível em:

<https://www.ibge.gov.br>. Acesso em: 20 set. 2017

MINISTERIO DO DESENVOLVIMENTO SOCIAL. Matriz de Informação Social, 2004 a 2015. Disponível em: <https://www. http://aplicacoes.mds.gov.br/sagidata/misocial/tabelas/mi_social.php> Acesso em: 3 jul. 2018

OLIVEIRA, R. C.; SILVEIRA NETO, R. M. Escolaridade, políticas sociais e a evolução da desigualdade regional de renda no Brasil entre 2003 e 2011: uma análise a partir das fontes de renda. Revista Econômica do Nordeste, Fortaleza, v. 44, n. 3, jul-set. 2013

PYATT, G.; CHEN, C.; FEI, J. The distribution of income by factor components. The Quarterly Journal of Economics, v.95, n.3, p.451-473, Nov. 1980.

PROGRAMA DAS NAÇÕES UNIDAS PARA O DESENVOLVIMENTO. Relatório Anual 2016. Disponível em:

$<$ http://www.br.undp.org/content/dam/brazil/docs/publicacoes/relatorio-pnud-

2016.pdf > Acesso em: 3 jul 2018 
RAMOS, L.; VIEIRA, M. L.. Desigualdade de rendimentos no Brasil nas décadas de 80 e 90: evolução e principais determinantes. Rio de Janeiro: IPEA, 2001. 22 p. (Texto para discussão, n. 803).

SANTOS, José Alcides Figueiredo. Mudanças de renda no Brasil: fatores espaciais, setoriais, educacionais e de status social. Soc. estado., Brasília, v. 30, n. 3, p. 749772, Dec. 2015

SCHWARTZMAN, S.. Redução da desigualdade, da pobreza, e os programas de transferência de renda. IETS - Instituto de Estudos do Trabalho e Sociedade, fev. 2006.

SILVEIRA NETO, R.; GONÇALVES, M. B. Mercado de trabalho, transferência de renda e evolução da desigualdade de renda no Nordeste do Brasil entre 1995 e 2005. In: ENCONTRO REGIONAL DE ECONOMIA DO NORDESTE, 12. 2007.

Fortaleza. Anais... Fortaleza, 2007

SINGER, P. Desenvolvimento e repartição da renda do Brasil. In: Tolipan, R.; Tinelli, A. C. (Org). A controvérsia sobre distribuição de renda e desenvolvimento. 2. Ed. Rio de Janeiro: Zahar, p. 73-104

SOARES, S. S. D. Distribuição de renda no Brasil de 1976 a 2004 com ênfase no período entre 2001 e 2004. Texto para Discussão, n. 1166. IPEA, fev. 2006, Brasília.

TAVARES, Maria Conceição. Da Substituição de Importações ao Capitalismo Financeiro. Rio de Janeiro: Zahar, 1972. 